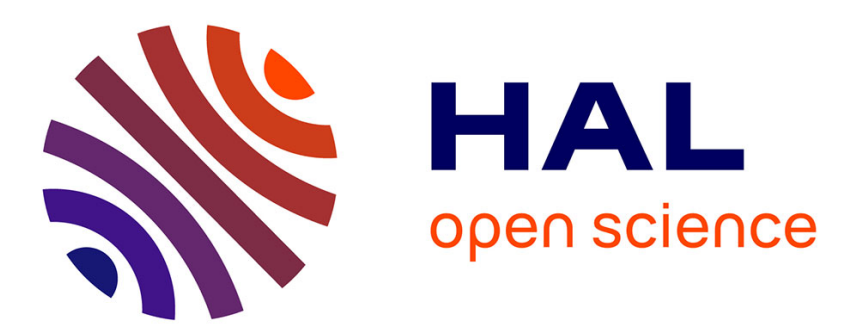

\title{
Average spectrum of spontaneous activity at the round window modified by sedation, anesthesia and salicylate
}

Y. Cazals, Z. Huang

\section{To cite this version:}

Y. Cazals, Z. Huang. Average spectrum of spontaneous activity at the round window modified by sedation, anesthesia and salicylate. Journal de Physique IV Proceedings, 1994, 04 (C5), pp.C5-415C5-418. 10.1051/jp4:1994587 . jpa-00253082

\section{HAL Id: jpa-00253082 https://hal.science/jpa-00253082}

Submitted on 1 Jan 1994

HAL is a multi-disciplinary open access archive for the deposit and dissemination of scientific research documents, whether they are published or not. The documents may come from teaching and research institutions in France or abroad, or from public or private research centers.
L'archive ouverte pluridisciplinaire HAL, est destinée au dépôt et à la diffusion de documents scientifiques de niveau recherche, publiés ou non, émanant des établissements d'enseignement et de recherche français ou étrangers, des laboratoires publics ou privés. 


\title{
Average spectrum of spontaneous activity at the round window modified by sedation, anesthesia and salicylate
}

\author{
Y. CAZALS and Z. HUANG \\ Laboratoire d'Audiologie Expérimentale, Inserm unité 229, Université Bordeaux II, Hôpital Pellegrin, \\ 33076 Bordeaux, France \\ ENT Department, First Affiliated Hospital, Hubei Medical School, Wuhan, China
}

\begin{abstract}
Résumé : The electrophysiological signal recorded at the round window of the cochlea reflects sensory and neural activity of the inner ear. Besides acoustically evoked responses, sometimes temporally averaged, which are usual means of functional assessement; recordings obtained in silent conditions and spectrally averaged reflect spontaneous auditory nerve activity as recently demonstrated. In this paper it is shown that averaged spectrum of spontaneous activity (ASSA) at the round window of guinea pigs, with permanently implanted electrodes, differs in awake versus sedated or anesthetized conditions. This casts some doubt upon the physiological significance of single-unit analyses of spontaneous auditory nerve activity. It is also shown in this paper that ASSA is modified by administration of salicylate even at a dose which does not induce threshold elevation. These observations set ASSA at the round window as a convenient and very sensitive physiological measure of spontaneous sensory-neural activity and provide much more convincing foundations for physiological exploration of tinnitus in animal models.
\end{abstract}

\section{INTRODUCTION}

Animal models of auditory pathologies offer unique opportunities to perform physiological studies in the perspective of better understanding, preventing and curing diseases affecting humans. This objective is often hampered by differences between animals and humans and also by possible alterations of normal physiological functioning in experimental conditions $(1,2,3)$. Tinnitus is probably the most physiologically mysterious pathology of audition and its medical management is very unsatisfactory $(4,5)$. From recent studies increased spontaneous sensori-neural activity seems to be a likely sign of tinnitus $(6,7,8,9,10,11)$, and average spectrum of spontaneous activity (ASSA) may be an appropriate measure $(9,12,13)$. The present study aimed at assessing the reliability of ASSA recorded from the round window in normal guinea pigs and at assessing ASSA alterations induced by high doses of salicylate which induce tinnitus in humans.

\section{METHODS}

Adult pigmented guinea pigs were used in these studies. They were chronically implanted with one electrode on the round window and two others on the frontal cortex. During all experiments animals were placed in a silent cabin and restrained in a holding box with an earphone placed one centimeter in front of their external acoustic meatus. To analyze spontaneous sensory-neural activity, signals were amplified 1000 times and filtered between $1 \mathrm{~Hz}$ and $10 \mathrm{kHz}$. They were then digitized with a 16 bits converter at a rate of $22050 \mathrm{~Hz}$ and stored in a microcomputer. For each recording 30 seconds of signal were taken, fast Fourier transforms were performed on 300 sucessive partitions of 2048 points and an average spectrum was finally computed. For determining compound action potential thresholds, averaging of about 200 responses evoked with a tone pip was performed and visual detection was used. Tone pips were sine waves gated with a linear rise/fall time of 2 milliseconds and no plateau. For sedating the animals xylazine was used at a dose of $10 \mathrm{mg} / \mathrm{kg}$, for anesthesia a mixture of xylazine at 10 $\mathrm{mg} / \mathrm{kg}$ with ketamine at $50 \mathrm{mg} / \mathrm{kg}$ was used. Salicylate was administered in one intramuscular injection, the two doses of 250 and $500 \mathrm{mg} / \mathrm{kg}$ were used.

\section{RESULTS}

ASSA at the round window exhibited a very similar pattern for all animals with a first peak around 50 hertz and another broad one around $1000 \mathrm{~Hz}$. The first peak around $50 \mathrm{~Hz}$ was not an artefact of power supply as a much finer spectral resolution did not show a component at $50 \mathrm{~Hz}$ or integer multiples. in addition this peak varied in frequency under various physiological conditions as indicated 

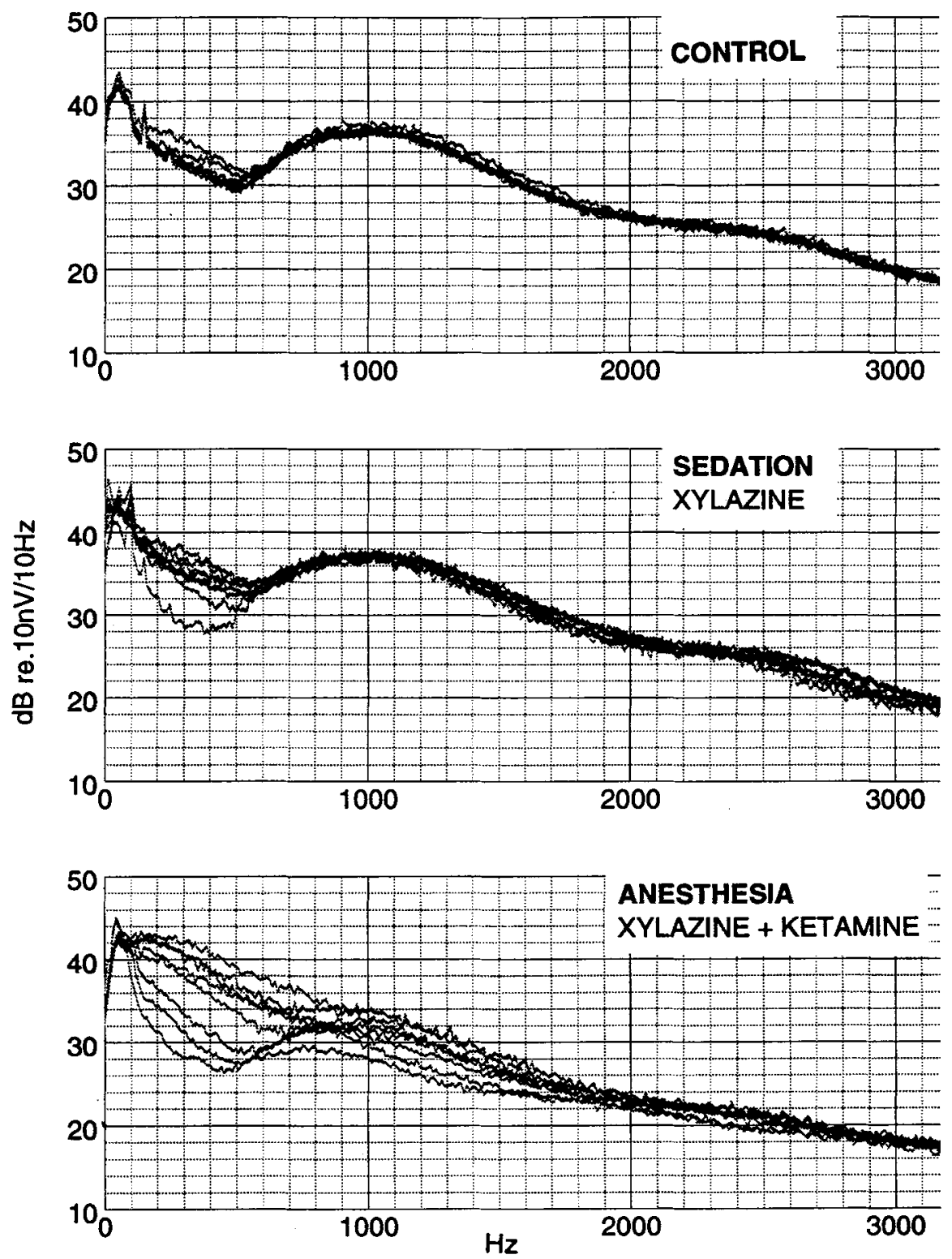

\section{FIGURE 1}

Top graph : ASSA obtained at intervals of one hour over 7 hours from an awake animal.

Middle graph : ASSA obtained before and 2, 3, 4, 5, 6 and 7 hours after sedative administration (top curves) and at $15 \mathrm{mn}$ and $1 \mathrm{~h}$ (bottom curves) after sedative administration.

Bottom graph : ASSA obtained before (middle curve), at 1,2 and 3 hours after anesthesia administration (bottom curves) and at 4, 5,6 and 7 hours (top curves) after anesthesia. 

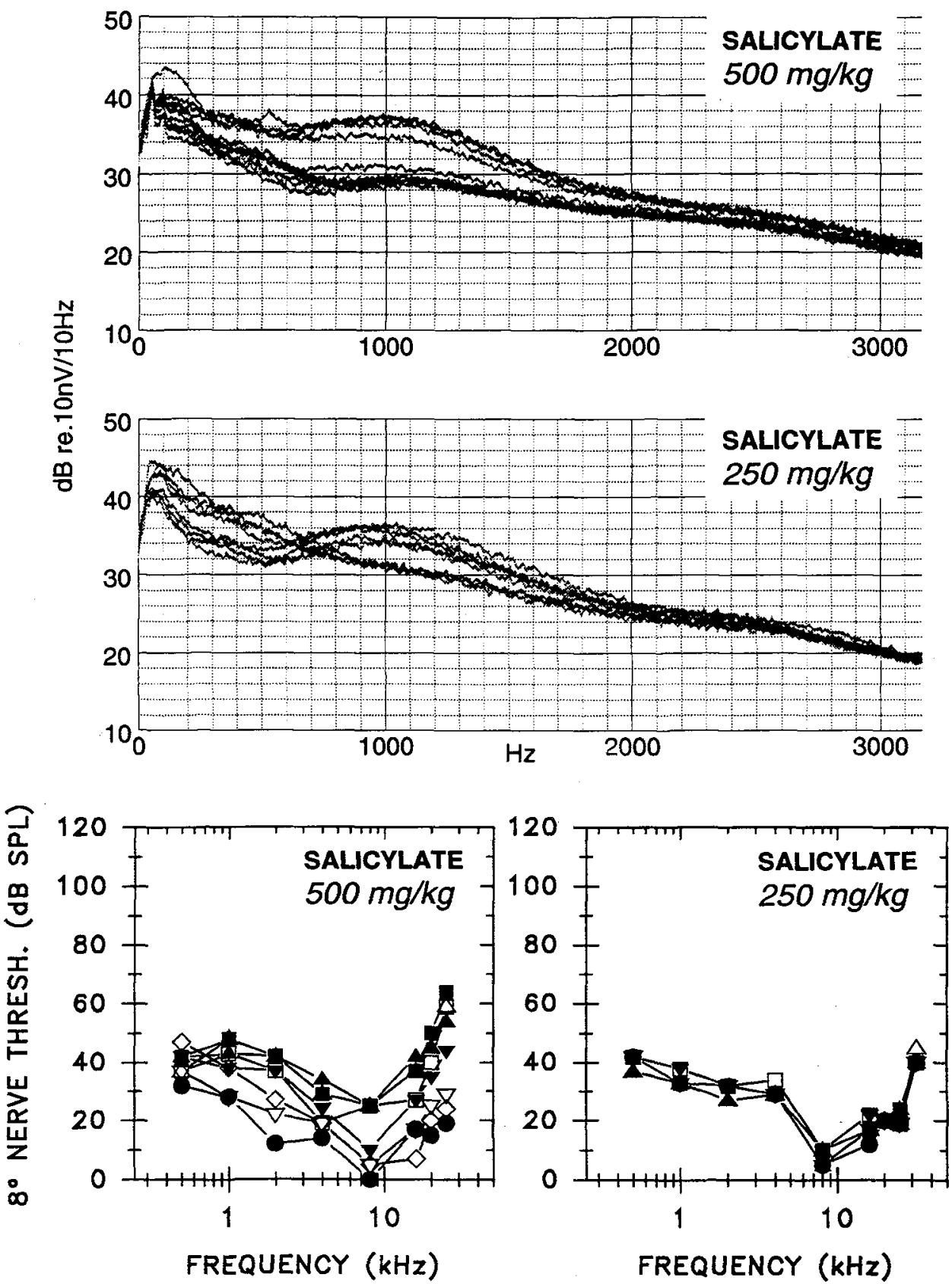

FIGURE 2

Top graph : ASSA obtained before and at $5 \mathrm{mn}, 30 \mathrm{mn}$ and $24 \mathrm{~h}$ after salicylate administration (upper curves) and at $1,2,3,4,6$ and $7 \mathrm{~h}$ (lower curves) after salicylate injection at $500 \mathrm{mg} / \mathrm{kg}$

Middle graph : ASSA obtained before and at 4, 5, 6 and $7 \mathrm{~h}$ after salicylate administration (upper curves at $1 \mathrm{kHz}$ ) and at 1,2 and $3 \mathrm{~h}$ (lower curves at $1 \mathrm{kHz}$ ) after salicylate injection at $250 \mathrm{mg} / \mathrm{kg}$.

Bottom graphs : left - audiograms obtained at the same times as for top graph, right audiograms obtained at the same times as for middle graph. 
later in this paper. Some animals which did not present a clear broad peak around $1000 \mathrm{~Hz}$, had some CAP threshold elevation at the high frequencies and were not considered in this paper. As illustrated in the top graph of figure 1 for an animal, the ASSA was very stable over 7 hours of recording showing variations of 1 to $2 \mathrm{~dB}$ with the $10.7 \mathrm{~Hz}$ resolution used in this study.

The second graph of figure 1 presents a decrease of about $6 \mathrm{~dB}$ observed mostly at $300-500 \mathrm{~Hz}$ five minutes after the administration of the sedative, one hour later the ASSA returned to pre-injection values. This pattern of ASSA alteration by xylazine was found very similar in the ten tested animals. The bottom graph of figure 1 illustrates ASSA modifications induced by anesthesia with xylazine-ketamine. One hour after anesthetic injection ASSA showed an increase of about $3 \mathrm{~dB}$ around $30 \mathrm{~Hz}$ associated with a large decrease of up to $10 \mathrm{~dB}$ around $300-500 \mathrm{~Hz}$ which extended up to $2000 \mathrm{~Hz}$ being of about 4 $\mathrm{dB}$ around $1000 \mathrm{~Hz}$. Three hours after anesthetic injection ASSA showed an increase of about $4 \mathrm{~dB}$ in the 100 to $1000 \mathrm{~Hz}$ region, two hours later this was reduced and the next day the animal being fully awake ASSA was identical to pre-anesthesia. All these alterations were systematically observed in the five animals tested.

In figure 2 are given examples of alterations of ASSA and of compound action potential audiograms obtained after administration of salicylate. The top graph together with the left audiogram at the bottom show results from one animal treated with a dose of $500 \mathrm{mg} / \mathrm{kg}$ of salicylate. ASSA showed a decrease between 100 to $3000 \mathrm{~Hz}$ reaching a maximum of about $8 \mathrm{~dB}$ around $1000 \mathrm{~Hz}$ which was observed over 6 hours after salicylate injection, a day later ASSA was similar to pre-injection. Audiograms indicated threshold elevations, of 10 to $30 \mathrm{~dB}$ increasing progressively at high frequencies, over a period of 6 hours after salicylate injection and no threshold elevation one day later. The middle graph and the right audiogram of figure 2 show effects of a dose of $250 \mathrm{mg} / \mathrm{kg}$ of salicylate. In the 4 hours post injection ASSA showed an increase of about $4 \mathrm{~dB}$ in the frequency region of 50 to $600 \mathrm{~Hz}$ associated with a decrease from about $600 \mathrm{~Hz}$ to $2000 \mathrm{~Hz}$ reaching a maximum of about $5 \mathrm{~dB}$ around $1000 \mathrm{~Hz}$. At 5, 6 and 7 hours post injection ASSA showed its pre-injection values. As indicated in the audiogram no threshold changes were observed. In the five tested animals similar patterns of ASSA and audiogram changes were observed but changes were large in some animal and much smaller in others, such individual variability in response to salicylate is well known (14).

\section{DISCUSSION}

Data from this study revealed the high reliability of ASSA measures at the round window and of its changes induced by sedation or anesthesia. They also demonstrated ASSA alterations induced by salicylate without threshold elevation of auditory nerve compound action potential.

In agreement with previous measures in the guinea pig and the cat $(9,12,13)$, data in this study show an ASSA broad peak around $1000 \mathrm{~Hz}$ which disappears for minimal threshold elevation at high frequencies suggesting, as previous measures of masking (12), that it originates from the cochlear base. This study reveals the existence of another peak around $50 \mathrm{~Hz}$ which was masked by recording artefact in previous reports $(12,13)$. Recordings in the cat $(9,13)$ report a peak around $200 \mathrm{~Hz}$ which was not seen in the guinea pig. Which physiological activity is reflected by these various peaks remains speculative but the alterations observed in sedated or anesthetized conditions cast some doubt upon the physiological significance of recordings of auditory nerve spontaneous activity in acute conditions.

The greater sensitivity of ASSA measures to alterations induced by salicylate compared with auditory nerve compound action potential measures is, for the physiologist, remarkable. In addition because this is coherent with the human experience of tinnitus as the first sign, before threshold elevation, of salicylate ototoxicity, ASSA appears as a very attractive new physiological tool to study tinnitus.

\section{REFERENCES}

1 - Galin D Auditory nuclei: distinctive response patterns to white noise and tones in unanesthetized cats. Science, 1964, $146,270-272$

2 - Cazals Y, Aran JM \& Hawkins JE Threshold elevation at high frequencies of the auditory nerve action potential in acute versus chronic recordings in guinea pigs. Hearing Res., 1980,2, 95-109.

3 - Dodd F \& Capranica RR A comparison of anesthetic agents and their effects on the response properties of the peripheral auditory system. Hearing Research, 1992, 62, 173-180.

4 - Cazals Y \& Bourdin M Etude acoustique des acouphènes. Rev. Laryngol., 1983, 104, 433-438.

5 - Cazals $Y$. Negrevergne $M$ \& Aran JM Electrical stimulation in man : hearing induction and tinnitus suppression. J. Am. Audiol. Soc., 1978, 209-213.

6 - Evans EF, Wilson JP \& Borerwe TA Animal models of tinnitus. In Tinnitus Ciba symposium vol. 85, Pitman London, $1981,103-138$.

7 - Evans EF \&Borerwe TA Ototoxic effects of salicylates on the responses of single cochlear nerve fibers and on cochlear potentials. Br. J. Audiology, 1982, 16, 101-108.

8 - Jastreboff PJ \& Sasaki CT Salicylate-induced changes in spontaneous activity of single units in the inferior colluculus of the guinea pig. J. Acoust. Soc. Am. 1986, 80, 1384-1391.

9 - Schreiner CE \& Snyder RL A physiological animal model of peripheral tinnitus. In Proceedings of 3rd international tinnitus seminar, Harsch Karlsnuhe. 1987, 100-106.

10 - Jastreboff PJ, Brennan JF \& Sasaki CT An animal model for tinnitus. Laryngoscope, 1988, 98, 280-286.

11 - Jastreboff PJ, Brennan JF, Coleman JK Phantom auditory sensation in rats: an animal model for tinnitus. Behav. Neurosci., 1988, 102-811-822.

12 - Dolan DF. Nuttall AL \& Avinash G Asynchronous neural activity recorded from the round window. J. Acoust. Soc. Am.. 1990, 87,2621-2627.

13 - Martin WH, Schwegler JW, Scheibelhoffer J \& Ronis ML Salicylate-induced changes in cat auditory nerve activity. Laryngoscope 1993, 103, 600-604.

14 - Cazals Y, Li XQ, Aurousseau C \& Didier A Acute effects of noradrenalin related vasoactive agents on the ototoxicity of aspirin: an experimental study in the guinea pig. Hearing Res., 1988, 36, 89-96. 